\section{FRI0387 DISEASE COURSE AND OUTCOMES DURING PREGNANCY IN PATIENTS WITH AXIAL SPONDILOARTHRITIS: COMPARISON BETWEEN TNFI USERS AND NAIVE PATIENTS}

Francesca Crisafulli ${ }^{1,2}$, Laura Andreoli ${ }^{1,2}$, Maria Chiara Gerardi ${ }^{1,2}$, Antía García Fernández ${ }^{3}$, Cecilia Nalli ${ }^{1}$, Matteo Filippini ${ }^{1}$, Roberto Gorla ${ }^{1}$, Marco Taglietti ${ }^{1}$, Micaela Fredi ${ }^{1}, 2$, Maria Grazia Lazzaroni ${ }^{1,2}$, Andrea Lojacono ${ }^{2,4}$ Sonia Zatti ${ }^{4}$, Franco Franceschini ${ }^{1,2}$, Angela Tincani ${ }^{1,2},{ }^{1}$ ASST Spedali Civili of Brescia, Rheumatology and Clinical Immunology Unit, Brescia, Italy, ${ }^{2}$ University of Brescia, Brescia, Italy; ${ }^{3}$ Ramon y Cajal University Hospital, Rheumatology, Madrid, Spain; ${ }^{4}$ ASST Spedali Civili of Brescia, Obstetrics and Gynaecology Unit, Brescia, Italy

Background: Axial Spondiloarthrtis (AxSpA) can be active during preg nancy, especially in those patients who discontinued TNFi at the beginning of pregnancy. The severity of flare during pregnancy can influence the gestational outcome and the attitude of the physician towards treatment.

Objectives: To describe: 1)the disease course of AxSpA during pregnancies in patients who never used TNFi (bio-naïve) and those who were TNFi users; 2)the severity of flares; 3)the impact of resuming TNFi in patients who experienced a flare during pregnancy (on both maternal disease control and gestational outcome).

Methods: Retrospective analysis of 18 prospectively-followed pregnancies from 2010 to 2018 in 15 patients with AxSpA. Two pregnancies ended in miscarriage, so they weren't considered for the analysis of flares during pregnancy. Active disease was defined as ASDAS-CRP >2.1. Flare was defined as an increase of ASDAS-CRP greater than 0.6 with CRP elevation and one of the followings: introduction or increase above $5 \mathrm{mg} /$ day of prednisone, introduction of CDMARD or bDMARD.

Results: At preconception visit, 2 patients were on treatment only with steroids, 1 with sulfasalazine and steroids and 9 with bDMARDs (5 etanercept, 2 adalimumab, 2 golimumab; 2 with steroids). At conception, 3 patients presented active disease. TNFi was stopped at positive pregnancy test in 7 pregnancies; 1 patient continued TNFi over pregnancy. Twelve out of $16(75 \%)$ patients had at least one disease flare $(4,10$ and 3 during $1^{\text {st }}, 2^{\text {nd }}$ and $3^{\text {rd }}$ trimester respectively). Among pregnancies with flare, medication resumed during pregnancy were steroids $(7,58 \%)$, cDMARDs ( 1 salazopyrine and 1 cyclosporine A, 17\%) and bDMARDs (4 etanercept and 1 certolizumab, $42 \%)$. Six patients (38\%) had a flare in postpartum period. Table 1 shows the comparison between pregnancies with and without flares during pregnancy.

By comparing the pregnancies of patients with and without history of TNFi use (table 2), we have registered 8 flares $(8 / 11,73 \%$ ) in the first group and 4 flare $(4 / 5,80 \%)$ in the second one. In the group of $\mathrm{TNFi}$ users, medications resumed during pregnancy were steroids in $5 / 11$ $(46 \%)$ and bDMARDs in 5/11 (46\%), whereas in the group TNFi naïve only in 1 pregnancy steroids was resumed and no bDMARDs were started. Mean ASDAS-CRP was higher in the group of TNF user.

For what concerned gestational outcome, we did not observe any SGA, pre-eclampsia and eclampsia. Two pregnancies ended with miscarriage and 2 with preterm birth (at 36 and 34 gestational weeks). Two patients had PROM and 1 pPROM (this patient refused to resume TNFi during pregnancy and her flare was treated with medium doses of prednisone). Conclusion: Three out of $4 \mathrm{AxSpA}$ patients with severe disease phenotype and history of TNFi use prior to pregnancy experienced a disease flare after TNFi discontinuation at conception. Conversely, AxSpA patients with mild disease phenotype had a similar rate of flare during pregnancy but less severe and without the need for chronic treatment during pregnancy. When resumed during pregnancy TNFi was able to control disease activity and to favor a good gestational outcome. In preconception counselling the continuation of TNFi during pregnancy should be discussed with the patients.

Disclosure of Interests: Francesca Crisafulli: None declared, Laura Andreoli: None declared, Maria Chiara Gerardi: None declared, Antía García Fernández: None declared, Cecilia Nalli: None declared, Matteo Filippini: None declared, Roberto Gorla: None declared, Marco Taglietti: None declared, Micaela Fredi: None declared, Maria Grazia Lazzaroni: None declared, Andrea Lojacono: None declared, Sonia Zatti: None declared, Franco Franceschini: None declared, Angela Tincani Consultant for: UCB, Pfizer, Abbvie, BMS, Sanofi, Roche, GSK, AlphaSigma, Lilly, Jannsen, Cellgene, Novartis

DOI: 10.1136/annrheumdis-2019-eular.7705
Table 1: clinical features, medication and disease activity in pregnancies with flare vs pregnancies

\begin{tabular}{|c|c|c|}
\hline & FLARE YES (12) & FLARE NO (4) \\
\hline \multicolumn{3}{|l|}{\begin{tabular}{|l} 
CUINICAL FEATURES \\
\end{tabular}} \\
\hline \begin{tabular}{|l|} 
Mean age at conception, years (SD) \\
\end{tabular} & $33(5.12)$ & $32.7(6.7)$ \\
\hline \begin{tabular}{|l} 
Mean Disease duration, months (SD) \\
\end{tabular} & $74.8(52)$ & $93(122.1)$ \\
\hline \begin{tabular}{|l|} 
Peripheral arthritis, $n(\%)$ \\
\end{tabular} & $4(33)$ & $2(50)$ \\
\hline \begin{tabular}{|l|} 
Enthesitis, $n(\%)$ \\
\end{tabular} & $3(25)$ & $2(50)$ \\
\hline Dactilitis, n (\%) & $1(8)$ & $0(0)$ \\
\hline \begin{tabular}{|l|l} 
Psoriasis, n (\%) \\
\end{tabular} & $3(25)$ & $1(25)$ \\
\hline IBD, (\%) & $2(17)$ & $1(25)$ \\
\hline \begin{tabular}{|l|} 
Uveitisi, $\mathrm{n}(\%)$ \\
\end{tabular} & $1(8)$ & $0(0)$ \\
\hline \multicolumn{3}{|l|}{\begin{tabular}{|l} 
MEDICATION \\
\end{tabular}} \\
\hline History of TNFi, $n(\%)$ & $8(67)$ & $3(75)$ \\
\hline History of $\mathrm{TNFi}>1, \mathrm{n}(\%)$ & $2(17)$ & $2(50)$ \\
\hline TNFi at preconception visit, $n(\%)$ & $6(50)$ & $2(50)$ \\
\hline \begin{tabular}{|l|l} 
TNFi stopped at pregnancy test+, $n(\%)$ \\
\end{tabular} & $3(25)$ & $1(25)$ \\
\hline cDMARDs history, $\mathbf{n}(\%)$ & $9(75)$ & $3(75)$ \\
\hline CDMARDs $>1, n(\%)$ & $2(17)$ & $1(25)$ \\
\hline \multicolumn{3}{|l|}{ DISEASE ACTIVITY } \\
\hline $\begin{array}{l}\text { ASDAS-CRP >2.1 at preconception visit, } \\
n(\%)\end{array}$ & $2(17)$ & $1(25)$ \\
\hline $\begin{array}{l}\text { Elevated CRP at preconception visit, } n \\
(\%)\end{array}$ & $0(0)$ & $1(25)$ \\
\hline $\begin{array}{l}\text { ASDAS-CRP >2.1 during } 1^{\text {gn trimester, } n} \\
(\%)\end{array}$ & $4(33)$ & $0(0)$ \\
\hline \begin{tabular}{|ll} 
Elevated CRP during $1^{1^{s}}$ trimester, $\mathrm{n}(\%)$ \\
\end{tabular} & $3(25)$ & 1(4) \\
\hline
\end{tabular}

Table 2: flare, medications at preconception visits and medications initiated during pregnancy in pregnancies of patients with history of TNFi use or not.

\begin{tabular}{|c|c|c|}
\hline & TNFi users & TNFi naive \\
\hline \multicolumn{3}{|l|}{ FLARE AND ASDAS-CRP } \\
\hline Flare during pregnancy ${ }^{*}$ & $8 / 11(73 \%)$ & $4 / 5(80 \%)$ \\
\hline Flare in post partum period & $5 / 12(42 \%)$ & $1 / 6(17 \%)$ \\
\hline ASDAS-CRP 1" TRIMESTER (mean) & 2.04 (SD 1.23) & 0.82 (SD 0.39) \\
\hline ASDAS-CRP $2^{\text {nd }}$ TRIMESTER (mean) & 2.54 (SD 1.31) & 1.55 (SD 0.82) \\
\hline ASDAS-CRP 3"TRIMESTER (mean) & 1.56 (SD 0.64) & $1.02(S D 0.99)$ \\
\hline ASDAS-CRP post partum (mean) & 2.46 (SD 0.73) & 1.53 (SD 1.34) \\
\hline \multicolumn{3}{|c|}{ MEDICATION AT PRECONCEPTIONAL VISIT } \\
\hline TNFi & $6 / 12(55 \%)$ & $0 / 6(0)$ \\
\hline Prednisone & $2 / 12(18 \%)$ & $1 / 6(17 \%)$ \\
\hline CDMARDS & $0 / 12(0)$ & $2 / 6(33 \%)$ \\
\hline \multicolumn{3}{|l|}{$\begin{array}{l}\text { MEDICATION RESUMED DURING } \\
\text { PREGNANCY * }\end{array}$} \\
\hline TNFi & $5 / 11(46 \%)$ & $0 / 5(0)$ \\
\hline Prednisone & $5 / 11(46 \%)$ & $1 / 5(20 \%)$ \\
\hline CDMARDS & $1 / 11(9 \%)$ & $1 / 5(20 \%)$ \\
\hline
\end{tabular}

two pregnancies ended in miscarriage were not considere

\section{FRI0388 SECUKINUMAB IMPROVES HEALTH-RELATED QUALITY OF LIFE IN PATIENTS WITH ANKYLOSING SPONDYLITIS, IRRESPECTIVE OF TIME SINCE FIRST DIAGNOSIS: POOLED RESULTS FROM THE SECUKINUMAB PHASE 3 TRIAL PROGRAM}

Atul Deodhar ${ }^{1}$, Annelies Boonen ${ }^{2}$, Gianfranco Ferraccioli ${ }^{3}$, Filip van den Bosch ${ }^{4}$, David Martinez ${ }^{5}$, Brian Porter ${ }^{6}$, Abhijit Shete $^{7}$, Isabelle Gilloteau ${ }^{7}$, Aurore Yocolly ${ }^{8}$, Vibeke Strand ${ }^{9} .{ }^{1}$ Oregon Health and Science University, Portland, United States of America; ${ }^{2}$ Maastricht University, Maastricht, Netherlands; ${ }^{3}$ Catholic University Medical School, Rome, Italy; ${ }^{4}$ Ghent University Hospital, Ghent, Belgium; ${ }^{5}$ RTI Health Solutions, Research Triangle Park, United States of America; ${ }^{6}$ Novartis Pharmaceuticals Corporation, New Jersey, United States of America; ${ }^{7}$ Novartis Pharma AG, Basel, Switzerland; ${ }^{8}$ Novartis Global Service Center, Dublin, Ireland; ${ }^{9}$ Stanford University, Palo Alto, United States of America

Background: Ankylosing spondylitis (AS) is a chronic rheumatic condition that has a negative impact on health-related quality of life (HRQOL). Secukinumab (SEC), a fully human anti-IL-17A monoclonal antibody, has been shown to effectively control AS symptoms and improve HRQoL.

Objectives: To evaluate the impact of SEC on HRQoL, assessed by the Short Form-36 Health Survey (SF-36), in pts with active AS stratified by time since first diagnosis ( $<2$ or $\geq 2$ yrs).

Methods: Pts were randomized to placebo (PBO) or SEC in MEASURE 1 (10 mg/kg intravenously followed by 150 or $75 \mathrm{mg} \mathrm{SC}$ ), MEASURE (150 or $75 \mathrm{mg} \mathrm{SC}$ ) and MEASURE 4 (150 mg SC with/without SC loading). At Wk 16 or Wk 24, depending on ASAS 20 response, pts on PBO were re-randomized to SEC. Mixed-models for repeated measures were used to evaluate changes in SF-36 from baseline (BL) to Wk 16; observed data are presented at Wk 52. The proportion of pts reporting improvements meeting/exceeding the minimal clinically important differences (MCID) for SF-36 physical (PCS responders) and mental component summary (MCS responders), and individual SF-36 domains was also 
assessed. Missing data were recorded as non-response and Fisher's exact test was used to compare the proportion of responders between groups at Wk 16. Only pooled data for pts receiving the licensed dose of SEC $(150 \mathrm{mg})$ are shown.

Results: Overall 739 patients were included, with 427 and 312 in the SEC $150 \mathrm{mg}$ and PBO groups, respectively. Of those, $37 \%$ and $36 \%$ of the SEC and PBO groups, respectively, were classified as $<2$ yrs since first AS diagnosis (Overall: 37\%). The mean time since AS diagnosis was similar for the $\mathrm{PBO}$ and SEC treatment groups in both the <2 yrs (approx. $0.80 \mathrm{yrs}$ ) and the $\geq 2$ yrs subgroups (approx.11 yrs). The least squares mean (LSM) changes in PCS from BL to Wk 16 were increased with SEC $150 \mathrm{mg}$ compared with $\mathrm{PBO}$, in both <2 yrs (PBO: 2.11; 150 $\mathrm{mg}: 6.44, \mathrm{p}<0.0001$ ) and $\geq 2$ yrs since diagnosis (PBO: $3.03 ; 150 \mathrm{mg}$ : $5.82, p<0.0001)$ groups. Significant increases were also reported in LSM changes in MCS scores from BL to Wk 16 with SEC $150 \mathrm{mg}$ in patients $<2$ yrs since diagnosis (PBO: 2.10; $150 \mathrm{mg}: 5.53, \mathrm{p}<0.01$ ), but not in the $\geq 2$ yrs group. Analysis of individual SF-36 domain scores showed improvements with SEC vs PBO in the overall population and in both time since diagnosis subgroups, except Role-Emotional and Mental Health in the $\geq 2$ yrs group (Figure). At Wk 16, the proportions of PCS responders were significantly higher with SEC $150 \mathrm{mg}$ vs PBO, regardless of time since diagnosis $(<2$ yrs: $\mathrm{PBO}=50.0 \%$, SEC $=73.6 \%, \mathrm{p}<0.01 ; \geq 2$ yrs: $\mathrm{PBO}=45.0 \%$, SEC $=69.8 \%, \mathrm{p}<0.0001)$. MCS responses were not significantly different with SEC vs $\mathrm{PBO}$ in either subgroup. Overall, improvements in SF-36 scores and clinically meaningful MCID responses with SEC were more prominent in the $<2$ yrs since diagnosis compared with the $\geq 2$ yrs group. Improvements in PCS, MCS, individual SF-36 domains and overall MCID responses were sustained to Wk 52 with SEC $150 \mathrm{mg}$.

Conclusion: Treatment with SEC $150 \mathrm{mg}$ resulted in significant, clinically meaningful, and sustained improvements in HRQoL. Although reported irrespective of time since AS diagnosis, improvements were more prominent in earlier diagnosed pts.

Acknowledgement: Study sponsored by Novartis. Medical writing support by Seren Communications, funded by Novartis.

Disclosure of Interests: Atul Deodhar Grant/research support from: AbbVie, Amgen, Eli Lilly, GSK, Janssen, Novartis, Pfizer, and UCB, Consultant for: AbbVie, Amgen, BMS, Eli Lilly, Janssen, Novartis, Pfizer, and UCB, Annelies Boonen: None declared, Gianfranco Ferraccioli Speakers bureau: LILLY, ROCHE, NOVARTIS, Filip van den Bosch Consultant for: AbbVie, BMS, Galapagos, Janssen, Lilly, Merck, Novartis, Pfizer and UCB, Speakers bureau: AbbVie, BMS, Janssen, Lilly, Merck, Novartis, Pfizer and UCB., David Martinez Consultant for: I developed the analyses of this study paid by the pharmaceutical., Brian Porter Shareholder of: Novartis, Employee of: Novartis, Abhijit Shete Shareholder of: Novartis Pharma AG, Employee of: Novartis Pharma AG, Isabelle Gilloteau Employee of: Employee of Novartis, Aurore Yocolly Employee of: Employee of Novartis, Vibeke Strand Consultant for: Samumed, LLC, AbbVie, Amgen, EMD Serono, Eupraxia, Flexion, Iroko, Novartis, Pfizer, Regeneron, Sanofi, SKK

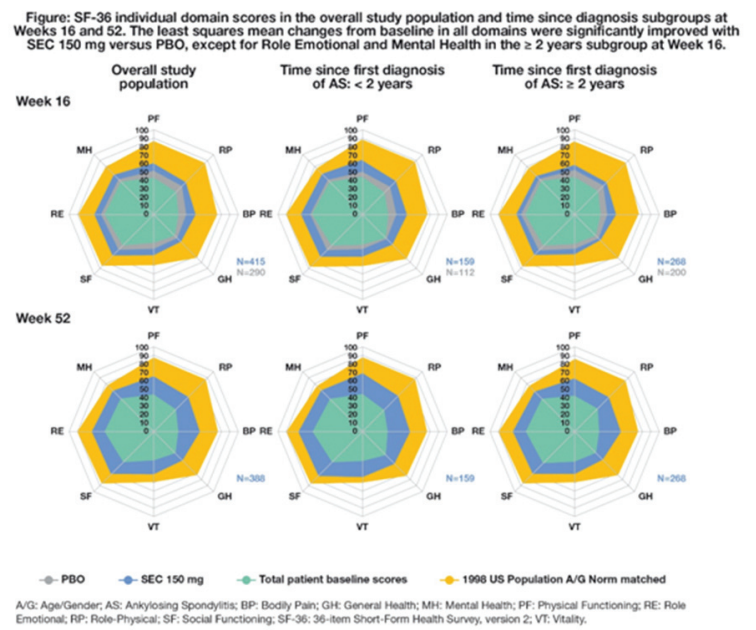

DOI: 10.1136/annrheumdis-2019-eular.2829

\section{FRI0389}

EFFECTIVENESS OF BIOLOGIC THERAPY ON DISEASE ACTIVITY IN ANKYLOSING SPONDYLITIS: A BIOBADASER III OBSERVATIONAL STUDY

Valentina Emperiale $^{1,2}$, Carlos Sánchez-Piedra ${ }^{2}$, Cristina Bohórquez ${ }^{1}$,

María Colazo ${ }^{3}$, Carlos Fernández-López ${ }^{4}$, Noemí Busquets ${ }^{5}$ Inmaculada Ros ${ }^{6}, \mathrm{~J}$.

M. Blanco ${ }^{7}$, Manuel Moreno ${ }^{8}$, Jose Campos Esteban ${ }^{9}$, Carlos Rodríguez-

Escalera $^{10}$, Fernando Sánchez-Alonso ${ }^{2}$, Juan Jesus Gomez-Reino ${ }^{11} .{ }^{1} \mathrm{HU}$

Príncipe de Asturias, Alcalá de Henares, Spain; ${ }^{2}$ Spanish Society of

Rheumatology, Research Unit, Madrid, Spain; ${ }^{3} \mathrm{H}$ de Burgos, Burgos, Spain; ${ }^{4} \mathrm{CHU}$ A Coruña, A Coruña, Spain; ${ }^{5} \mathrm{HG}$ de Granollers, Granollers, Spain; ${ }^{6} \mathrm{H}$ Son Llàtzer, Palma de Mallorca, Spain; ${ }^{7} \mathrm{HU}$ de Basurto, Bilbao, Spain; ${ }^{8} \mathrm{HCU}$ Virgen de la Arrixaca, El Palmar, Spain; ${ }^{9} \mathrm{HU}$ Puerta de Hierro, Majadahonda, Spain; ${ }^{10} \mathrm{H}$ de Jaén, Jaén, Spain; ${ }^{11} \mathrm{HCU}$ de Santiago, Santiago de Compostela, Spain

Background: The advent of biologic therapy (BT) in ankylosing spondylitis (AS) has substantially benefited patients with inadequate response to conventional therapy. However, it is known patients with inadequeate response to a 1st BT have worse response to 2 nd and further lines.

Objectives: To analyze the effectiveness of BT in biologic-naïve and biologic-experienced real-world AS patients, measuring response through change in activity indexes (ASDAS-CRP and BASDAI) and percentage of low activity and inactive disease at 12 months.

Methods: Data were obtained from BIOBADASER III, an ongoing observational longitudinal multicenter cohort of patients with rheumatic diseases treated with BT or targeted synthetic DMARDs. Patients were divided into 2 groups, according to their state before entering the study: BT-naïve (BTn) receiving their $1^{\text {st }} \mathrm{BT}$, and $\mathrm{BT}$-experienced $(\mathrm{BTe})$ receiving their $2^{\text {nd }}$ or further BT; regardless of the specific drug they received. Disease activity indexes (DAl) were collected at baseline and after 12 months of BT; mean and SD was calculated for each group and interpreted according to ASDAS disease activity states and, since not established, analogous categories previously used for BASDAI ( $<2$ inactive, $\geq 2<4$ low, $\geq 4$ $<6$ high, $\geq 6$ very high) ${ }^{1}$. Clinical response was assessed by ASDAS improvement cut-offs ( $\geq 1.1$ clinically important improvement (CII), $\geq 2$ major improvement $(\mathrm{MI}))$ and BASDAI CII $(\geq 1.1)^{2}$, BASDAI change $(\Delta)$ $\geq 2$ or BASDAI50.

Results: 846 patients, $(29.3 \%$ women, mean age 47.6 years $)$ were included, 422 BTn and 424 BTe. Mean DAl results (table 1): at baseline, AS had high disease activity by BASDAI $(>4)$ and ASDAS (>2.1 to $<3.5$ ). At 12 months, disease activity was low on both groups (BASDAl $<4$, ASDAS $>1.3$ to $<2.1$, reaching BASDAl Cll; $\triangle \mathrm{BASDAl} \geq 2$ was only achieved in BTn. No group reached BASDAI50. ASDAS CII was reached in all groups, but $\mathrm{Ml}$ was not seen. Percentage of patients achieving low disease activity and inactive disease are summarized at table 2, being overall higher for the BTn compared to the BTe group.

Table 1. Mean disease activity indexes evolution

\begin{tabular}{lcccccc}
\hline \multirow{2}{*}{$\begin{array}{l}\text { Activity } \\
\text { index }\end{array}$} & \multicolumn{2}{c}{ Biologic-naïve (BTn) } & \multicolumn{3}{c}{ Biologic-experienced (BTe) } \\
\cline { 2 - 7 } & $\begin{array}{l}\text { Baseline } \\
\text { (SD) }\end{array}$ & $\begin{array}{c}\mathbf{1 2} \text { months } \\
\text { (SD) }\end{array}$ & $\Delta$ & $\begin{array}{c}\text { Baseline } \\
\text { (SD) }\end{array}$ & $\begin{array}{c}\text { 12 months } \\
\text { (SD) }\end{array}$ & $\Delta$ \\
\hline BASDAI & $5.5(2.0)$ & $3.2(1.0)$ & 2.3 & $5.6(2.3)$ & $3.9(2.3)$ & 1.7 \\
& $n=422$ & $n=287$ & & $n=424$ & $n=244$ & \\
ASDAS- & $3.2(1.4)$ & $1.7(1.0) n=64$ & 1.5 & $3.4(1.5)$ & $2.0(0.9) n=50$ & 1.4 \\
PCR & $n=120$ & & & $n=95$ & & \\
\hline
\end{tabular}

Table 2. Percentage of low disease activity and inactive disease by BASDAI and ASDAS

\begin{tabular}{lcc}
\hline $\begin{array}{l}\text { Disease activity } \\
\text { states }\end{array}$ & $\begin{array}{c}\mathbf{n}, \% \text { achieved at 12 months on } \\
\text { BTn }\end{array}$ & $\begin{array}{c}\mathbf{n} \% \text { achieved at } \mathbf{1 2} \text { months on } \\
\text { BTe }\end{array}$ \\
\hline BASDAl low activity & $120,41.8 \%$ & $72,29.5 \%$ \\
BASDAl inactive & $73,25.4 \%$ & $58,23.8 \%$ \\
disease & & \\
ASDAS low activity & $21,32.8 \%$ & $11,22 \%$ \\
ASDAS inactive & $23,35.9 \%$ & $15,30 \%$
\end{tabular}

Conclusion: The mean disease activity on patients starting biologic therapy is high. A clinically important improvement is met after 12 months of therapy, irrespectively of the index used or the prior use of biologics. The delta in DAl is bigger in the biologic-naïve group who receive the $1^{\text {st }}$ BT. The biologic-naïve group also reaches a higher percentage of low disease activity and inactive disease. Further analysis is needed to see if these tendencies remain after separating the groups per type of biologic drug. 